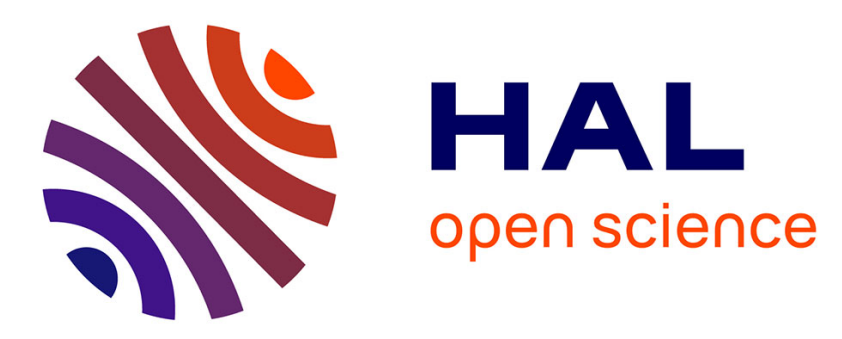

\title{
Ferrocenyl Quinone Methide-Thiol Adducts as New Antiproliferative Agents: Synthesis, Metabolic Formation from Ferrociphenols, and Oxidative Transformation
}

Yong Wang, Marie-Aude Richard, Siden Top, Patrick M. Dansette, Pascal Pigeon, Anne Vessières, Daniel Mansuy, Gérard Jaouen

\section{To cite this version:}

Yong Wang, Marie-Aude Richard, Siden Top, Patrick M. Dansette, Pascal Pigeon, et al.. Ferrocenyl Quinone Methide-Thiol Adducts as New Antiproliferative Agents: Synthesis, Metabolic Formation from Ferrociphenols, and Oxidative Transformation. Angewandte Chemie, 2016, 55 (35), pp.1043110434. 10.1002/anie.201603931 . hal-01345781

\section{HAL Id: hal-01345781 \\ https: / hal.sorbonne-universite.fr/hal-01345781}

Submitted on 15 Jul 2016

HAL is a multi-disciplinary open access archive for the deposit and dissemination of scientific research documents, whether they are published or not. The documents may come from teaching and research institutions in France or abroad, or from public or private research centers.
L'archive ouverte pluridisciplinaire HAL, est destinée au dépôt et à la diffusion de documents scientifiques de niveau recherche, publiés ou non, émanant des établissements d'enseignement et de recherche français ou étrangers, des laboratoires publics ou privés. 
Angew. Chem. Ed. Int., 2016, DOI: 10.1002/anie.201603931

\title{
Ferrocenyl Quinone Methide-Thiol Adducts as New Antiproliferative Agents: Synthesis, Metabolic Formation from Ferrociphenols, and Oxidative Transformation
}

Yong Wang, Marie-Aude Richard, Siden Top," Patrick M. Dansette, Pascal Pigeon, Anne Vessières, Daniel Mansuy, and Gérard Jaouen*

[*] Dr. Y. Wang, Dr. M.-A. Richard, Dr. S. Top, Dr. P. Pigeon, Dr. A. Vessières, Prof. G. Jaouen Sorbonne Universités, UPMC Univ Paris 06, UMR 8232, IPCM, F-75005 Paris, France CNRS, UMR 8232, IPCM, F-75005 Paris, France PSL, Chimie ParisTech, 11 rue Pierre et Marie Curie, F-75005 Paris, France

E-mail: gerard.jaouen@chimie-paristech.fr, siden.top@chimie-paristech.fr

Dr. P. M. Dansette, Dr. D. Mansuy

Laboratoire de Chimie et Biochimie Pharmacologiques et Toxicologiques, UMR 8601

CNRS,Université Paris Descartes, PRES Paris Cité Sorbonne

45 rue des Saints Pères, 75270 Paris Cedex 06, France

E-mail:Daniel.Mansuy@parisdescartes.fr

\begin{abstract}
Ferrociphenols (FCs) and their oxidized, electrophilic quinone methide metabolites (FC-QMs) are organometallic compounds related to tamoxifen that exhibit strong antiproliferative properties. To evaluate the reactivity of FC-QMs towards cellular nucleophiles, we studied their reaction with selected thiols. A series of new compounds resulting from the addition of these nucleophiles, the FCSR adducts, were thus synthesized and completely characterized. Such conjugates are formed upon metabolism of FCs by liver microsomes in the presence of NADPH and thiols. Some of them exhibit antiproliferative properties comparable to those of their FC precursors. Under oxidizing conditions they either lead to their FC-QM precursors or to new quinone methides containing the SR moiety, FC-SRQM. These results not only provide interesting data about the reactivity and mechanism of antiproliferative effects of FCs, but also open the way towards new series of organometallic anti-tumor compounds.
\end{abstract}


We are currently witnessing strong signs of interest in contributions to biological science provided by new structures from the domain of inorganic chemistry. ${ }^{[1]}$ Long overshadowed by an all-encompassing interest in organometallic complexes in catalysis, the bioorganometallic chemistry of transition metals has slowly revealed its unique potential, particularly in terms of medicinal applications, ${ }^{[2]}$ including optimized space-filling for enzyme inhibition purposes, ${ }^{[3]}$ redox activity on specific targets, ${ }^{[4]}$ and antiproliferative effects by Ru catalysts on cancer cells. ${ }^{[5]}$ We can add to these functional attributes the property of intracellular multi-targeting of some anticancer candidates, which could be of interest in delaying or inhibiting problems of resistance ${ }^{[6]}$ In light of its potential, this area clearly demands further exploration, and indeed the current growth in interest underlines this. ${ }^{[7]}$

In this context we designed and studied organometallic structures with strong antiproliferative potential, namely ferrociphenols, which have the unusual property of possessing a [ferrocenyl-enephenol] motif that is active on cancer cells in a redox environment, ${ }^{[8]}$ allowing the generation of a primary active metabolite of the quinone methide type. ${ }^{[9]}$ Products $\mathbf{F C 1}, \mathbf{F C 2}$ and $\mathbf{F C} 3$ are typical of the active ferrociphenols related to tamoxifen; they are oxidized by chemical oxidants or by liver microsomes into quinone methide FC1-QM, FC2-QM and FC3-QM, respectively (Figure 1). ${ }^{[9 b, 10]}$ Biologically, these species operate via mechanisms of senescence and apoptosis depending on the concentration of compounds and the nature of cancer cells. ${ }^{[11]}$ This type of behavior may provide access to the treatment of cancers that are currently incurable due to their failure to respond to proapoptotic stimuli.
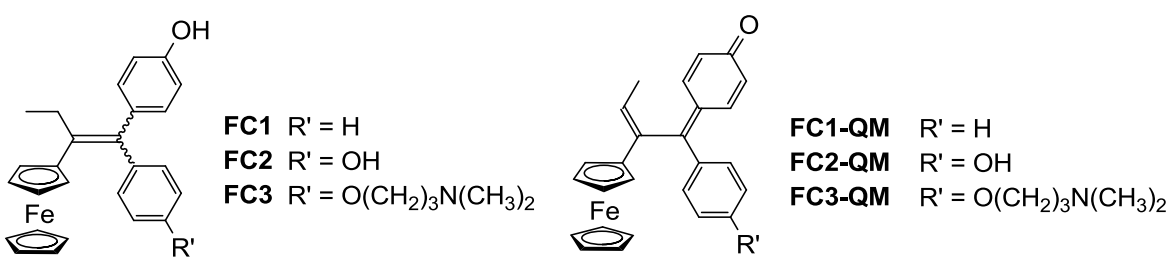

Figure 1. Ferrociphenols FCs and the corresponding quinone methides FC-QMs.

QMs are active species that can react with various nucleophiles inside the cell, such as peptides or proteins bearing thiols or selenols. Such reactions between QM and nucleophiles in vivo could lead to cell death via interference with oxidative stress or inactivation of enzymes. ${ }^{[12]}$ We recently reported that targeting thioredoxin reductases by ferrocenyl quinone methides could affect cellular redox balance in Jurkat cancer cells and may be partly responsible for the antiproliferative activity of ferrociphenols. ${ }^{[13]}$ Therefore, it becomes particularly important to undertake a study on the reaction of ferrocenyl QMs with selected nucleophiles. Here we present our results on the reaction of thiol nucleophiles such as glutathione (GSH), $\mathrm{N}$-acetyl-L-cysteine methyl ester (NACM) and mercaptoethanol (ME) with FC-QMs. A series of new compounds resulting from this reaction, the FC-SR adducts, were thus synthesized chemically and also identified upon metabolism of FCs by liver microsomes in the presence of NADPH and thiols. These organometallic thiol adducts not only exhibit potent antiproliferative properties but also show unique behavior under oxidative conditions.

An efficient synthesis of the desired FC-SR adducts involved a nucleophilic attack of thiols on FC-QMs in the presence of a base (Scheme 1). These adducts were formed as a mixture of stereoisomers because of the existence of $Z$ - and $E$-isomers at the level of the double bond and the presence of a chiral carbon (see for instance Chart SI1 for the stereoisomers of the FC1-SR adducts). Their structures were established by various spectroscopic techniques including an X-ray structure for FC1ME, which confirmed the 1,8-addition of ME on the quinone methide scaffold (Figure 2). ${ }^{[14]}$ Under physiological conditions ( $50 \mathrm{mM}$ phosphate buffer, $37^{\circ} \mathrm{C}$ ), we observed the formation of around $40 \%$ FC3-SR from the incubation of FC3-QM in the presence of excess NACM or ME at pH 5. This underlined the high reactivity of ferrocenyl QMs towards thiols which made the 1,8 Michael-type 
addition possible even at an acidic $\mathrm{pH}$ that was much lower than the $\mathrm{pKa}$ value of thiol deprotonation $(\sim 8.3)$.

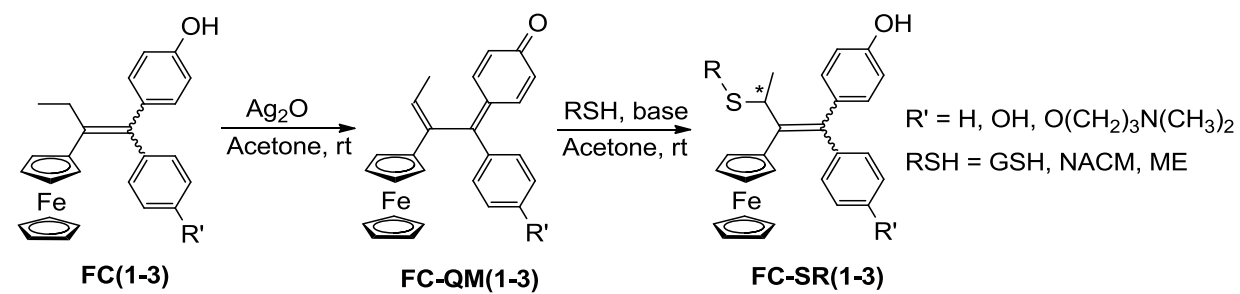

Scheme 1. General method for the synthesis of the FC-SR adducts.

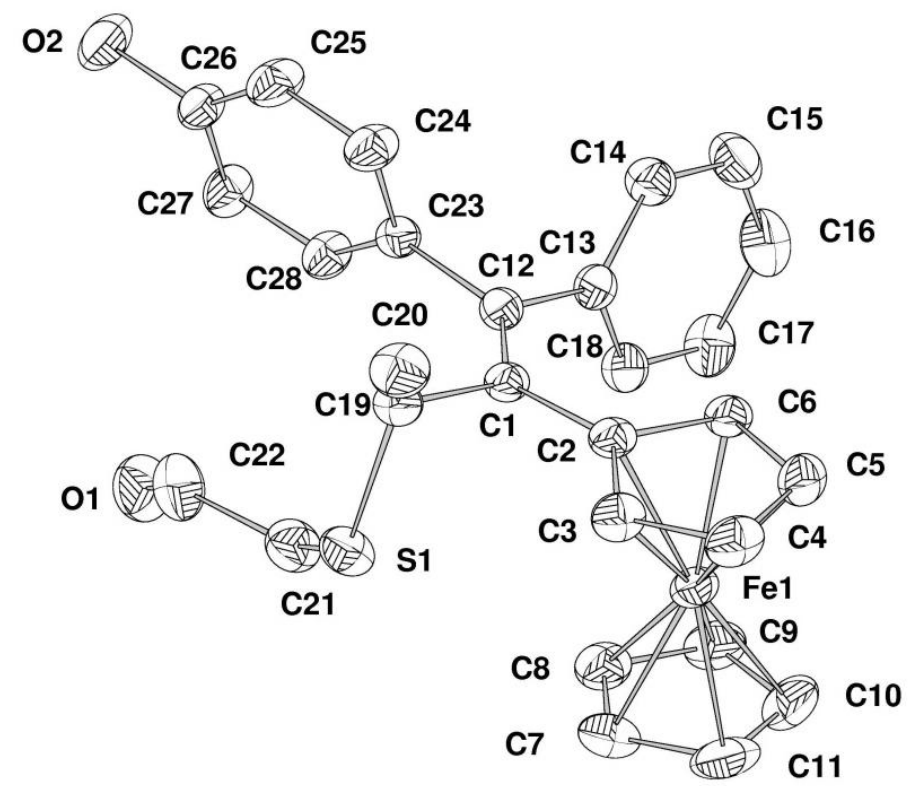

Figure 2. Molecular structure of FC1-ME as its $(S)$ - $E$ form, thermal ellipsoids are shown at $50 \%$.

Incubation of ferrociphenols with rat liver microsomes in the presence of NADPH (liver microsomes and NADPH: LM) and various thiols led to FC-SR adducts, in addition to the cyclized indene, FC-CP, and allylic alcohols, FC-AA (Scheme 2), metabolites already observed under identical incubations performed in the absence of thiols. ${ }^{[10]}$

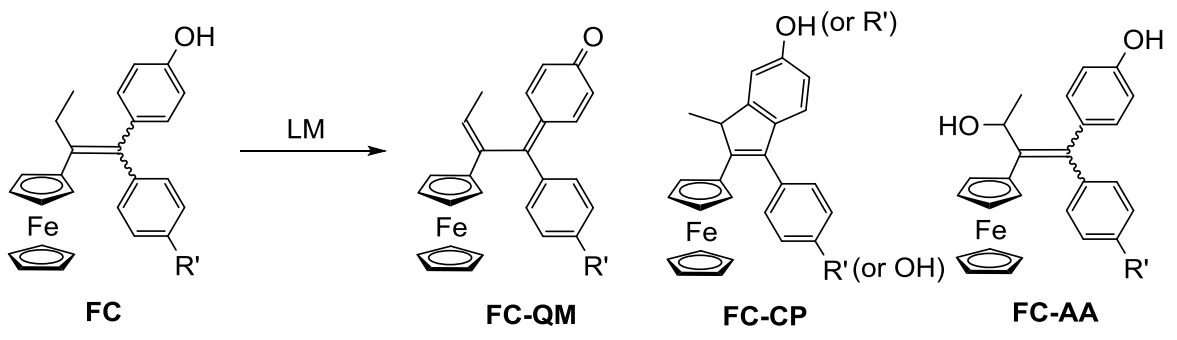

Scheme 2. Products obtained from incubation of $\mathbf{F C}(\mathbf{1}-\mathbf{3})$ with liver microsomes and NADPH (LM); $\mathrm{R}^{\prime}=\mathrm{H}, \mathrm{OH}, \mathrm{O}\left(\mathrm{CH}_{2}\right)_{3} \mathrm{NMe}_{2}$.

The FC-SR metabolites exhibited HPLC retention times and MS characteristics identical to those found for authentic samples. The proportion of the conjugates formed upon microsomal incubation of FC1-3 in the presence of GSH, NACM, or ME relative to all metabolites varied between 5 and $40 \%$. 
Interestingly, the adducts formed in the presence of GSH represented about $40 \%$ of all metabolites for FC2 and FC3 while this proportion decreased to only about 10\% for FC1. By comparison, microsomal incubation of 4-hydroxy-tamoxifen, 4-OHTAM, in the presence of GSH has been reported to only give a very small amount of quinone methide-GSH adduct. ${ }^{[15]}$

Table 1. Antiproliferative activity of ferrocenyl compounds against MDA-MB231 cells)

\begin{tabular}{|c|c|c|c|}
\hline Compound & $\mathrm{IC}_{50}(\mu \mathrm{M})^{[\mathrm{a}]}$ & Compound & $I C_{50}(\mu M)^{\mid a}$ \\
\hline FC1 & $1.5 \pm 0.1^{[c]}$ & FC2-NACM $^{[D]}$ & $1.0 \pm 0.2$ \\
\hline FC1-QM & $7.2 \pm 0.5^{[c]}$ & FC3 & $0.5^{[\mathrm{c}]}$ \\
\hline FC1-ME $E^{[b]}$ & $2.2 \pm 0.1$ & FC3-QM & $1.8 \pm 0.2^{[\mathrm{c}]}$ \\
\hline FC1-NACM ${ }^{[b]}$ & $1.5 \pm 0.1$ & FC3-ME ${ }^{[b]}$ & $1.6 \pm 0.3$ \\
\hline FC1-SG ${ }^{[b]}$ & $>10$ & FC3-NACM ${ }^{[b]}$ & $4.8 \pm 0.2$ \\
\hline FC2 & $0.6 \pm 0.1^{[c]}$ & FC3-SG ${ }^{[b]}$ & $>10$ \\
\hline $\mathrm{FC}-\mathrm{ME}^{[\mathrm{b}]}$ & $0.9 \pm 0.1$ & 4-ОНТАМ & $30 \pm 0.6^{[\mathrm{d}]}$ \\
\hline
\end{tabular}

[a] Measured after 5 days of culture (mean of two independent experiments in quadruplicate $\pm \mathrm{SD}$ ). [b] mixture of all stereoisomers. [c] Values from ref. [10]. [d] $L_{50}$ values from ref. [18].

The antiproliferative activity of synthesized FC-SR compounds against hormone-refractory breast cancer MDA-MB-231 cells is shown in Table 1. We have already shown that quinone methides, FC1QM and FC3-QM, were less active than their parent compounds, FC1 and FC3 ${ }^{[9 b]}$ This weaker activity could be attributed to the chemical reactivity and unstability of QMs in the incubation medium. Interestingly, the antiproliferative effects of adducts FC1-ME and FC1-NACM were close to that of FC1 and even better than that of FC1-QM. The same phenomenon was also found for compounds FC2-ME and FC2-NACM, which had similar $\mathrm{IC}_{50}$ values around $0.9 \mu \mathrm{M}$ that were comparable to those of their ferrociphenol precursor. By contrast, GSH adducts, FC1-SG and FC3-SG, exhibited IC 50 $_{50}$ values higher than $10 \mu \mathrm{M}$. This weak activity of FC-SG compounds should be due to the much more difficult membrane penetration of these hydrophilic compounds into the cells. In the case of the FC3 series, FC3-ME and FC3-NACM were 3 and 10 times less active than FC3, respectively. It is likely that this decreased cytotoxicity could be due, as in the case of the GSH adducts, to the more difficult membrane penetration of these adducts that contain two hydrophilic side chains. One can assume that when formed inside the cells from metabolism of ferrociphenols, at the level of the endoplasmic reticulum and close to the important cell targets, these FC-SR adducts would exhibit much higher antiproliferative effects. Anyway, the FC-SR adducts constitute a new class of potent antiproliferative compounds. Moreover, our results suggest that the capture of FC-QMs by nucleophilic thiols in vivo may preserve the antiproliferative effects of the ferrociphenols and their QM metabolites by avoiding the formation of the inactive indene FC-CP metabolites (Scheme 2).

The FC-SR adducts share the same [ferrocenyl-ene-phenol] motif than their FC parent compounds. Thus, the antiproliferative activity of FC-SR could come from their ability to be oxidized into quinone methides. In order to explore this possibility, we first studied the chemical oxidation of FC-SR by $\mathbf{A g}_{2} \mathrm{O}$ in acetone (Scheme 3). After $30 \mathrm{~min}$ at $20^{\circ} \mathrm{C}$, the ${ }^{1} \mathrm{H}$ NMR spectrum of the mixture clearly showed the quantitative formation of FC-QM. This showed that the FC-SR adducts coming from the addition of thiols on FC-QMs may lead back to their FC-QM precursor in the presence of an oxidant. Interestingly, the FC-QMs obtained from this reaction were mainly in their Z- form, whereas the FC-QMs formed from direct oxidation of FCs were predominantly in their $E$-form. ${ }^{[9 b]}$ Thus, both precursor compounds FCs and their FC-SR metabolites could generate FC-QMs under chemical oxidation conditions. The reversibility of the addition of thiols to QMs or $\alpha, \beta$-unsaturated carbonyl compounds has been well studied and is referred to as the thiyl radical pathway. ${ }^{[16]}$ The reversible reaction of 4-OHTAM-QM with GSH was also reported to occur under physiological conditions. ${ }^{[15]}$ In the case of the reaction of FC- 
SR with $\mathrm{Ag}_{2} \mathrm{O}$, it is likely that a quinone radical derived from a one-electron oxidation of FC-SR was first formed. Elimination of a SR radical would then lead to FC-QM (Scheme 4, Path A). The formation of (Z)-FC-QM as the major isomer may be explained by a steric effect. SR is a bulky group compared to $\mathrm{H}$ and the methyl group and, to minimize steric hindrance, SR should position itself at the opposite side of the ferrocenyl group (Scheme 5). Then, elimination of the SR group from this position should lead to the formation of (Z)-FC-QM.

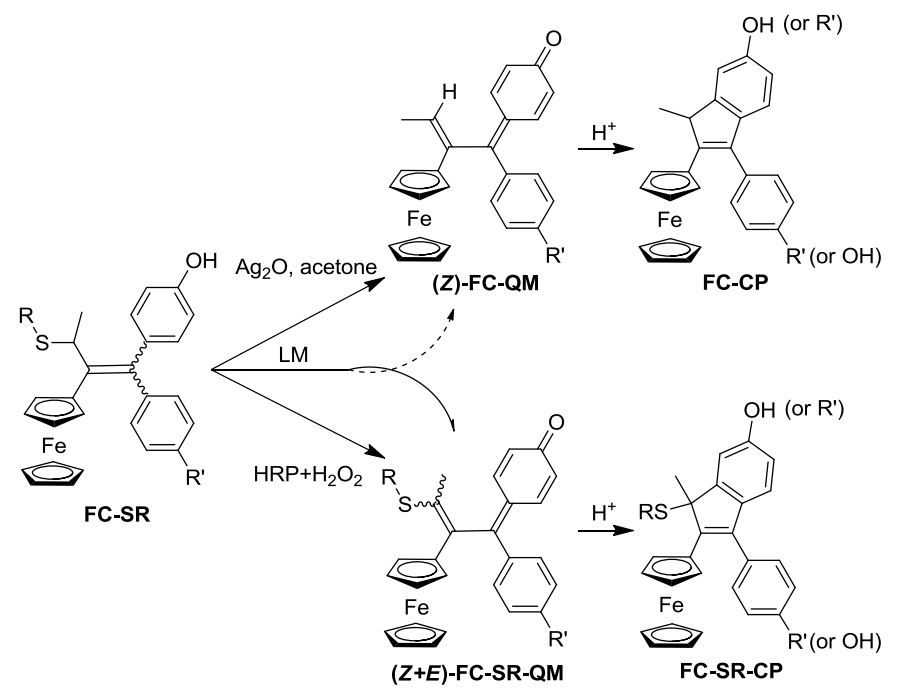

Scheme 3. Fates of the FC-SR adducts under oxidizing conditions.

To further evaluate the possible fates of the FC-SR adducts under more physiological oxidative conditions, we have studied their oxidation either by the horseradish peroxidase (HRP)/ $\mathrm{H}_{2} \mathrm{O}_{2}$ system or by rat liver microsomes in the presence of NADPH. Incubation of FC3-SG or FC3-NACM with $\mathrm{H}_{2} \mathrm{O}_{2} / \mathrm{HRP}$ for just a few seconds led to the formation of a major new product that could be detected by UV-vis spectroscopy and LC-MS. The new product showed a strong absorbance around $415 \mathrm{~nm}$ that is characteristic of $\mathrm{QMs}$, and its mass spectrum $\left(E S I^{+}\right)$exhibited a molecular ion corresponding to FC3-SG-QM (or FC3-NACM-QM), which is derived from a two-electron oxidation of the starting FC3SR adduct (Scheme 4, Path B). This product appeared only transiently, as its acid-catalyzed cyclization led to the corresponding indene compound FC3-SR-CP (Scheme 3) and prevented the isolation of the novel FC3-SR-QM.

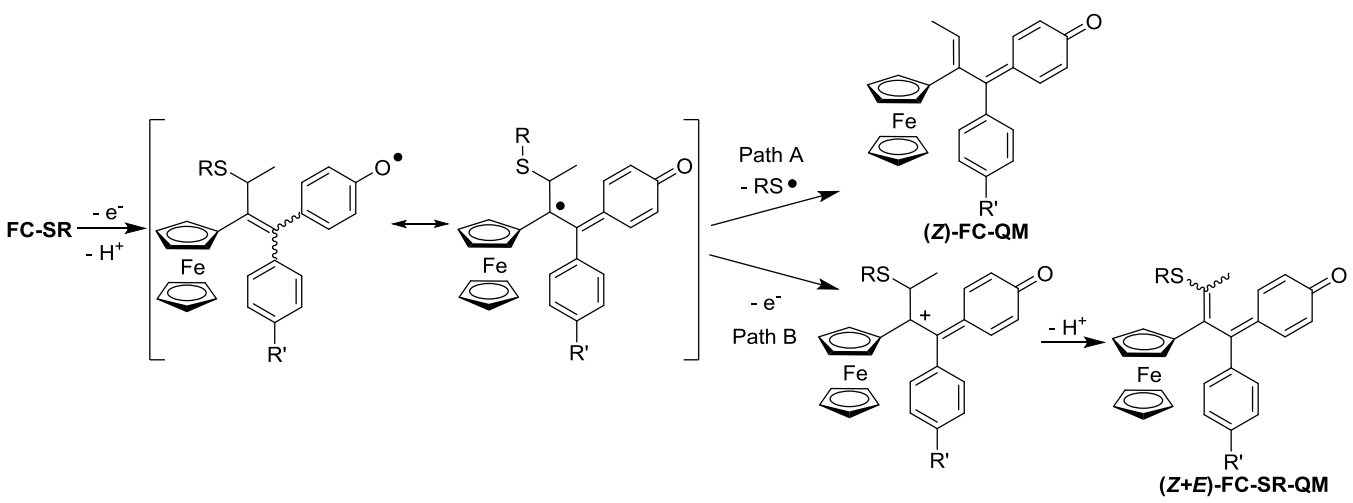

Scheme 4. Proposed oxidative evolution of FC-SR adducts. 


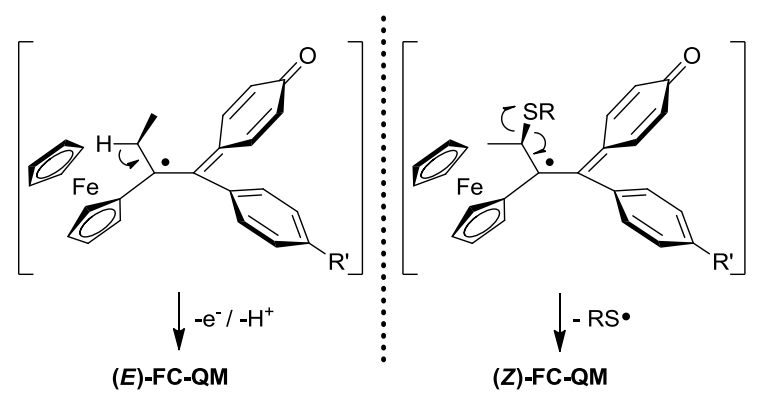

Scheme 5. Proposed mechanism of the formation of $(E)$ - and (Z)-FC-QM

Incubation of the FC3-SR adducts (with SR = SG or NACM) with liver microsomes in the presence of NADPH led, after workup, to indene derivatives FC3-SR-CP and FC3-CP that should result from the acid-catalyzed cyclization of FC3-SR-QM and FC3-QM. FC3-CP was characterized by comparison of its HPLC retention time and MS spectrum with those of a previously described authentic sample ${ }^{[10]}$ and FC3-SR-CP was characterized by its UV-vis and MS spectra. The FC3-SR-CP products were the major metabolites, as the FC3-SR-CP/FC3-CP ratio was around 85:15 and 98:2 in the case of SR = $S G$ and $S R=N A C M$, respectively.

The above results showed that oxidation of FC-SR adducts may either give back their FC-QM precursors or lead to new quinone methides retaining the SR moiety, FC-SR-QMs, as a function of the oxidizing medium (Schemes 3 and 6). Their oxidation by $\mathrm{Ag}_{2} \mathrm{O}$ led to $\mathrm{FC}-\mathrm{QMs}$ whereas their oxidation by $\mathrm{H}_{2} \mathrm{O}_{2} / \mathrm{HRP}$ or by liver microsomes in the presence of NADPH led mostly to FC-SR-QMs. It seems that, under the two latter oxidizing conditions that are closer to the in vivo situation, the presence of a ferrocenyl group at the level of the quinone radical formed upon one-electron oxidation of FC-SR would favor the formation of a ferrocenyl a-carbenium ion (Scheme 4, Path B) which subsequently would lose a proton to give FC-SR-QM.

In comparison, an HPLC study of the slow evolution of FC3-SG in phosphate buffer alone for one month showed the formation of only 5\%-10\% of the indene product FC3-SG-CP and the absence of FC3-CP. By contrast, under the same conditions, the 4-OHTAM-SG adduct led to 4-OHTAM-QM. ${ }^{[15]}$ This result shows an important role played by the ferrocenyl group which is to facilitate the formation of a quinone carbenium ion from the quinone radical intermediate derived from the one-electron oxidation of FC-SR. The well-known ability of metallocenes to stabilize adjacent $\alpha$-carbenium ions should explain the formation of the quinone carbenium ion shown in Scheme 4 and that of organometallic QM-retaining thiols FC-SR-QM after loss of a proton. This role of ferrocene as a carbenium ion-forming "inducer" provides a new addition to the toolbox of ferrocene in organometallics, in addition to its role as an intramolecular oxidation "antenna" and a stabilized carbenium ion "modulator" that we reported previously. ${ }^{[9 a, 17]}$ These various roles played by the ferrocenyl group on the ferrociphenol scaffold could explain the better antiproliferative activity of ferrociphenols when compared to tamoxifen.

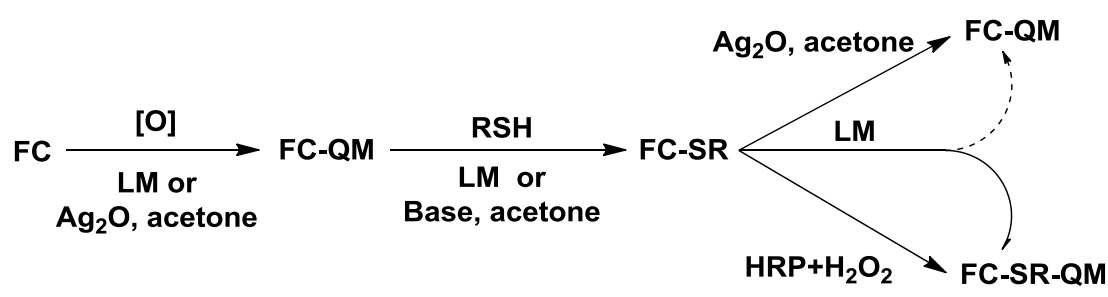

Scheme 6. Steps involved in the oxidations of ferrociphenols. 
In summary, the aforementioned results showed that the metabolism of ferrociphenols $\mathbf{F C}(\mathbf{1 - 3})$ by liver microsomes in the presence of NADPH and thiols led to new metabolites resulting from the 1,8Michael addition of the thiols on quinone methide intermediates FC-QM(1-3). Some of the FC-SR adducts exhibited antiproliferative effects towards hormone-resistant cancer cells comparable to those of the corresponding ferrociphenols. Moreover, these adducts can be further oxidized to give novel QMs which can participate again in the events that can lead to cell death. In particular, their oxidation by liver microsomes in the presence of NADPH mainly led to new quinone methides containing the sulfur moiety FC-SR-QMs, together with minor amounts of FC-QMs. These data showed the existence of a unique mode of metabolic oxidation of ferrociphenols FCs with the successive formation of two classes of reactive, electrophilic metabolites, the FC-QMs and FC-SR-QMs, as well as possible intermediate carbenium ions stabilized by the ferrocene moiety (Scheme 4), that could lead to irreversible damage to cell macromolecules and be at the origin of the antiproliferative effects of ferrociphenols. This unique metabolic oxidation profile of ferrociphenols may offer new ideas not only for determining the mechanism of action of ferrociphenols, but also for the rational design of new organometallics for the treatment of resistant cancers.

\section{Acknowledgements}

Agence Nationale de la Recherche (ANR-10-BLAN-706, Mecaferrol) and Feroscan are gratefully acknowledged for financial support. We thank P. Herson (Labex Michem, Université Pierre et Marie Curie, Paris, IPCM) for the X-ray structure determinations

Keywords: antitumor agents $\bullet$ glutathione $\cdot$ liver microsomes $\bullet$ Michael addition $\bullet$ organometallic

\section{References}

[1] N. P. E. Barry, P. J. Sadler, Chem. Commun. 2013, 49, 5106-5131.

[2] E. A. Hillard, A. Vessieres, G. Jaouen, in Medicinal Organometallic Chemistry, Vol. 32 (Eds.: G. Jaouen, N. Metzler-Nolte), Springer, Heidelberg, 2010, pp. 81-117.

[3] M. Dörr, E. Meggers, Curr. Opin. Chem. Biol. 2014, 19, 76-81.

[4] P. Messina, E. Labbé, O. Buriez, E. A. Hillard, A. Vessières, D. Hamels, S. Top, G. Jaouen, Y. M. Frapart, D. Mansuy, C. Amatore, Chem. Eur. J. 2012, 18, 6581-6587.

[5] J. J. Soldevila-Barreda, I. Romero-Canelón, A. Habtemariam, P. J. Sadler, Nat. Commun. 2015, 6,6582

[6] J. M. Hearn, I. Romero-Canelon, A. F. Munro, Y. Fu, A. M. Pizarro, M. J. Garnett, U. McDermott, N. O. Carragher, P. J. Sadler, Proc. Natl. Acad. Sci. U. S. A. 2015, 112, E3800E3805.

[7] a) G. Gasser, I. Ott, N. Metzler-Nolte, J. Med. Chem. 2011, 54, 3-25; b) C. G. Hartinger, N. Metzler-Nolte, P. J. Dyson, Organometallics 2012, 31, 5677-5685; c) F. Cisnetti, A. Gautier, Angew. Chem. Int. Ed. 2013, 52, 11976-11978; Angew. Chem. 2013, 125, 12194-12196; d) M. A. Cinellu, I. Ott, A. Casini, in Bioorganometallic Chemistry, Wiley, 2014, pp. 117-140; e) A. A. Nazarov, C. G. Hartinger, P. J. Dyson, J. Organomet. Chem. 2014, 751, 251-260. 
[8] a) S. Top, A. Vessières, G. Leclercq, J. Quivy, J. Tang, J. Vaissermann, M. Huché, G. Jaouen, Chem. Eur. J. 2003, 9, 5223-5236; b) M. Görmen, P. Pigeon, S. Top, E. A. Hillard, M. Huché, C. G. Hartinger, F. de Montigny, M.-A. Plamont, A. Vessières, G. Jaouen, ChemMedChem 2010, 5, 2039-2050.

[9] a) E. Hillard, A. Vessières, L. Thouin, G. Jaouen, C. Amatore, Angew. Chem. Int. Ed. 2006, 45, 285-290; Angew. Chem. 2005, 45, 285-290; b) D. Hamels, P. M. Dansette, E. A. Hillard, S. Top, A. Vessieres, P. Herson, G. Jaouen, D. Mansuy, Angew. Chem. Int. Ed. 2009, 48, 9124-9126; Angew. Chem. 2009, 121, 9288-9290; c) G. Jaouen, S. Top, in Advances in Organometallic Chemistry and Catalysis, Ed.: J. L. P. Armando, Wiley, New Jersey, 2014, pp. 563-580.

[10] M.-A. Richard, D. Hamels, P. Pigeon, S. Top, P. M. Dansette, H. Z. S. Lee, A. Vessières, D. Mansuy, G. Jaouen, ChemMedChem 2015, 10, 981-990.

[11] a) A. Vessières, C. Corbet, J. M. Heldt, N. Lories, N. Jouy, I. Laios, G. Leclercq, G. Jaouen, R.A. Toillon, J. Inorg. Biochem. 2010, 104, 503-511; b) C. Bruyère, V. Mathieu, A. Vessières, P. Pigeon, S. Top, G. Jaouen, R. Kiss, J. Inorg. Biochem. 2014, 141, 144-151; c) G. Jaouen, A. Vessieres, S. Top, Chem. Soc. Rev. 2015, 44, 8802-8817.

[12] a) S. J. Dougan, A. Habtemariam, S. E. McHale, S. Parsons, P. J. Sadler, Proc. Natl. Acad. Sci. U. S. A. 2008, 105, 11628-11633; b) F. Giannini, G. Suss-Fink, J. Furrer, Inorg. Chem. 2011, $50,10552-10554$.

[13] A. Citta, A. Folda, A. Bindoli, P. Pigeon, S. Top, A. Vessières, M. Salmain, G. Jaouen, M. P. Rigobello, J. Med. Chem. 2014, 57, 8849-8859.

[14] The supplementary crystallographic data for this paper is contained in 1454701 (FC1-ME). These data can be obtained free of charge from The Cambridge Crystallographic Data Centre via www.ccdc.cam.ac.uk/data_request/cif.

[15] P. W. Fan, F. Zhang, J. L. Bolton, Chem. Res. Toxicol. 2000, 13, 45-52.

[16] F. Dénès, M. Pichowicz, G. Povie, P. Renaud, Chem. Rev. 2014, 114, 2587-2693.

[17] Y. Wang, P. Pigeon, S. Top, M. J. McGlinchey, G. Jaouen, Angew. Chem. Int. Ed. 2015, 54, 10230-10233.

[18] F. Zhang, P. W. Fan, X. Liu, L. Shen, R. B. van Breemen, J. L. Bolton, Chem. Res. Toxicol. 2000, 13, 53-62. 
FC-SR adducts resulting from the addition of thiols on ferrocenyl quinone methides FC-QMs, are potent organometallic antiproliferative compounds. They were synthesized chemically and also identified upon metabolism of ferrociphenols FCs by liver microsomes in the presence of $\mathrm{NADPH}$ and thiols. These thiol adducts not only exhibit unique oxidative behaviors but also open the way towards new series of organometallic antitumor compounds.
Yong Wang, Marie-Aude

Richard, Siden Top, Patrick M. Dansette, Pascal Pigeon, Anne Vessières, Daniel Mansuy, ${ }^{*}$ and Gérard Jaouen*

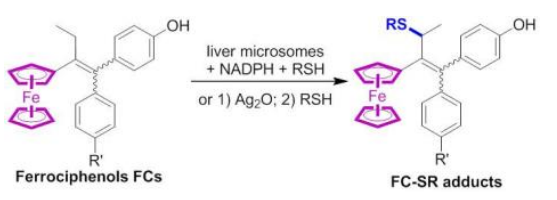

Page No. - Page No.

Ferrocenyl Quinone MethideThiol Adducts as New Antiproliferative Agents: Synthesis, Metabolic Formation from Ferrociphenols and Oxidative Transformation 